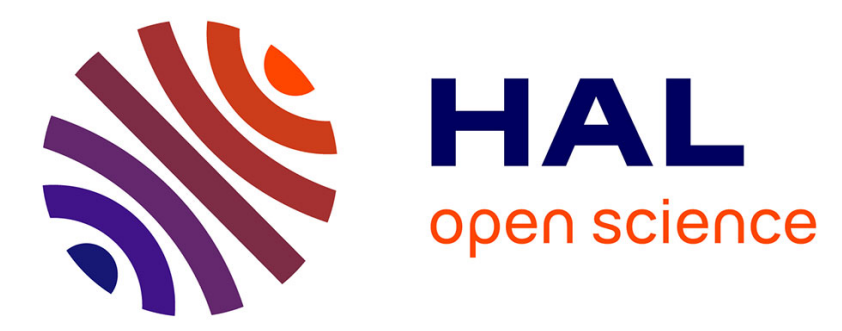

\title{
A Wave to Wire model of the SEAREV Wave Energy Converter
}

\author{
Christophe Josset, A. Babarit, A.H. Clement
}

\section{To cite this version:}

Christophe Josset, A. Babarit, A.H. Clement. A Wave to Wire model of the SEAREV Wave Energy Converter. Proceedings of the Institution of Mechanical Engineers, Part M: Journal of Engineering for the Maritime Environment, 2007, 221 (2), pp.81-93. 10.1243/14750902JEME48 . hal-00699486

\section{HAL Id: hal-00699486 \\ https://hal.science/hal-00699486}

Submitted on 20 Mar 2019

HAL is a multi-disciplinary open access archive for the deposit and dissemination of scientific research documents, whether they are published or not. The documents may come from teaching and research institutions in France or abroad, or from public or private research centers.
L'archive ouverte pluridisciplinaire HAL, est destinée au dépôt et à la diffusion de documents scientifiques de niveau recherche, publiés ou non, émanant des établissements d'enseignement et de recherche français ou étrangers, des laboratoires publics ou privés. 


\title{
A wave-to-wire model of the SEAREV wave energy converter
}

\author{
C Josset $^{1}$, A Babarit ${ }^{2}$, and A H Clément ${ }^{2 *}$ \\ ${ }^{1}$ Laboratoire de Thermocinétique de Nantes, Nantes Cedex, France \\ ${ }^{2}$ Laboratoire de Mécanique des Fluides, Ecole Centrale de Nantes, Nantes, France
}

\begin{abstract}
This paper describes a numerical wave-to-wire model of the second-generation wave energy converter called SEAREV. Governing equations are given in the time domain for the motion of the masses involved in the device and for the hydraulic power take-off (PTO) used to convert the motion into electricity. The hydrodynamic forces are derived using the standard linear potential theory. The memory term in the radiation force is replaced by additional states using the Prony method in order to change the equation of motion into the ordinary differential equation form. The PTO is composed of hydraulic rams, an accumulator, and a hydraulic generator, which delivers electricity when there is enough energy stored in the accumulator.

Using the MATLAB Simulink tool, the equation of motion is solved to simulate the full device (including the power take-off) from the incident wave to the electricity delivered to the grid. Simulation results are presented in the paper and comparisons are made with a simpler PTO: a linear damper. They show that the torque applied to the hydraulic PTO must exceed a threshold to start absorbing energy, unlike the linear damping model. They also show that the power production can be very discontinuous, depending on the level of the incident wave power. This is due to the fact that the generator considered can transform the energy stored in the accumulator faster than the energy transmitted by the rams into the accumulator. It could therefore be interesting to use several generators to adapt the electrical energy production to the level of incident wave power, or a generator that could work efficiently at part load in order to achieve continuous energy production.
\end{abstract}

Keywords: wave energy converter, wave-to-wire, numerical model, hydraulic power take-off

\section{INTRODUCTION}

Two complementary tools exist for designing efficient wave energy converters (WECs). The first tool is tank testing of small-scale models. It is a powerful tool, since results on models can be reliably related to the motion and the efficiency of the full-scale device. However, it is expensive and the designer needs a new model each time the shape is changed. By comparison, numerical modelling is much cheaper and is easy to make simulations of many different shapes of the same device. However, if a high level of accuracy of the response is needed, the central processing unit (CPU) time can quickly become huge. Designers

* Corresponding author: Laboratoire de Mécanique des Fluides, CNRS UMR6598, Ecole Centrale de Nantes, 1, Rue de la Noë, Nantes 44300, France.email: Alain.Clement@ec-nantes.fr usually start their investigation into a new wave energy concept by developing a fast and simple numerical model and then tank-testing models to investigate their behaviour further.

Frequency domain models of wave energy converters allow fast computation of the response of the device, and so extensive optimization [1] , but they use a linearized equation of motion. To investigate the behaviour of a system containing non-linear elements, a time-domain model is needed. For example, to assess the benefit brought by a nonlinear control method such as latching control, Hals et al. built such a time-domain model of a heaving buoy [2].

In wave energy converters, the power take-off (PTO) is a component that can be strongly nonlinear. In reference [3], Sà da Costa et al. give the equation of motion for an electric PTO associated 
with the Archimedes wave-swing device, and solve it using the MATLAB/simulink tool in the time domain.

In this paper, a hydraulic PTO, composed of a hydraulic ram, an accumulator, and a hydraulic generator, is considered. Falcao [4] gives equations for a hydraulic PTO associated with a heaving buoy, but solves the problem with several assumptions, such as an infinite accumulator and no generator. Here an even more realistic model of the PTO is considered, since it has a finite accumulator, a generator, and a hydraulic ram with compressible fluid. This PTO is associated with a model of the SEAREV device. The result is a full model of the SEAREV from the incident wave to the wire connected to the grid.

The equations of motion of the device are given in the first part of this paper, for a generic PTO. Then a full description of the hydraulic PTO is given in the second part. Equations of this specific PTO are given and the instantaneous force applied by the PTO on the device is derived. By coupling the equation of motion of the device and the PTO equations, the full equation of the device dynamics is derived. By integrating them numerically, it was possible to simulate the electricity production of the device for any given incident wave. Results of the simulations are presented in the last part of the paper.

\section{THE SEAREV DEVICE}

The SEAREV device is a floating device, completely enclosed, with an internal moving mass. Under the action of the waves, the floating hull and the internal moving mass start to move, each one with its own motion. The relative motion between the floating body and the moving mass is used to drive a generator via a hydraulic device, the PTO.

This device has many advantages.

1. All the moving parts are located inside the hull of the floating body, so they are protected from the action of sea water. Thus, the maintenance costs and the risk of failure are expected to be lower than for a system whose moving parts are in contact with sea water.

2. The internal mass is a large heavy cylinder featuring an off-centred gravity centre (Fig. 1), which is the main difference to the PS frog device [5]. This means that the mechanism needs no end stops. The inner cylinder is able to make several full revolutions around its horizontal axis or, from another point of view, the floating body can do a full revolution around the cylinder without destruction. The device is therefore expected to have a high survivability in extreme waves.

3 . The device does not need any external reference. It is a self-referenced WEC, which means that each part of the device, the hull and the cylinder, is a reference for the other. As it does not use the seabed as a reference, it needs only slack moorings, which are naturally less expensive than tight ones.

\subsection{Assumptions and notation}

The floating body (Fig. 1) is assumed to have two vertical planes of symmetry. It is also assumed that the axis of the internal cylinder is perpendicular to the main symmetry plane of the floating body and that the direction of propagation of the waves is

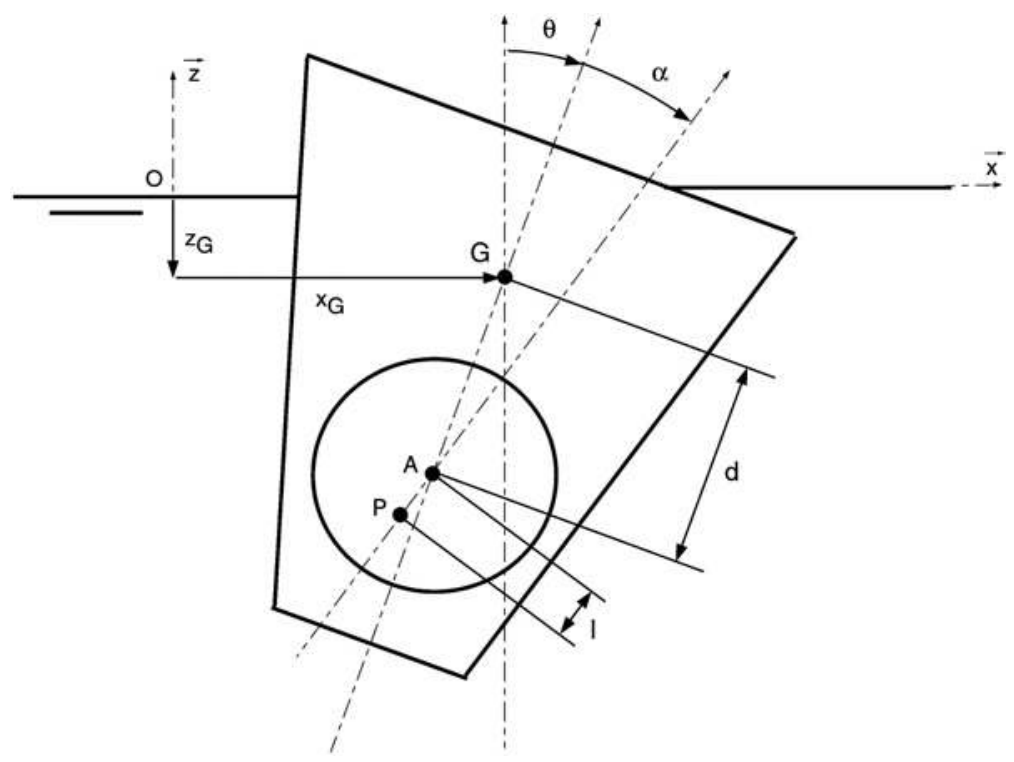

Fig. 1 SEAREV: notation 
parallel to this plane. Under these assumptions, in a two-dimensional incident wave train, the floating body moves only in the surge, heave, and pitch modes. For the device, the motion takes place in the $(x \mathrm{Oz})$ plane.

Let $x_{\mathrm{G}}$ be the surge motion and $z_{\mathrm{G}}$ the heave motion of the centre of gravity $G$ of the floating body, $\theta$ the pitch motion along the $y$ axis and $\alpha$ the relative motion between the floating body and the inner pendulum (the PTO system functions due to $\alpha$ ). Let $m_{\mathrm{b}}$ be the floating body mass, $I_{\mathrm{b}}$ its inertia, $m_{\mathrm{p}}$ the inner pendulum mass, and $I_{y}$ its inertia. Let $l=\mathrm{AP}$, the distance between the centre of rotation $\mathrm{A}$ of the inner pendulum and its own centre of gravity $\mathrm{P}$, and $d=\overline{\mathrm{GA}}$, the distance between the centre of gravity of the floating body and the centre of rotation of the pendulum.

It is assumed that the amplitude of the waves and the resulting motion of the body are sufficiently small to validate the classical linear theory approach.

\subsection{Equations}

Let $\boldsymbol{X}=\left(\begin{array}{llll}x_{\mathrm{G}} & z_{\mathrm{G}} & \theta & \alpha\end{array}\right)^{\mathrm{T}}$ be the position vector. In the time domain, the equations of motion are

$$
\begin{aligned}
\left(\mathbf{M}(\boldsymbol{X}, \dot{\boldsymbol{X}})+\boldsymbol{\mu}_{\infty}\right) \ddot{\boldsymbol{X}}= & \boldsymbol{F}_{\mathrm{ex}}(t)-\int_{0}^{t} \mathbf{H}(t-\tau) \dot{\boldsymbol{X}}(\tau) \mathrm{d} \tau \\
& -\mathbf{K}_{\mathrm{H}} \mathbf{Z}-\boldsymbol{F}_{\mathrm{g}}(\boldsymbol{X}, \dot{\boldsymbol{X}})-\boldsymbol{F}_{\mathrm{c}}(\boldsymbol{X}, \dot{\boldsymbol{X}}) \\
& -\boldsymbol{F}_{\mathrm{PTO}}(t, \boldsymbol{X}, \dot{\boldsymbol{X}})
\end{aligned}
$$

where

$\boldsymbol{F}_{\text {ex }}$ represents the hydrodynamic excitation force due to the incoming and diffracted waves. For random sea simulations, the excitation force is derived by discretizing the standard ITTC energy spectrum [6] and using a random phase generator (see reference [7] for more details).

$\mu_{\infty}$ is the hydrodynamic added mass.

The radiation force has been written as a convolution product according to the well-known Cummins' decomposition [8], $\mathbf{H}(t)$ being the memory function of the radiation force.

$\mathbf{K}_{\mathrm{H}}$ is the hydrostatic stiffness matrix of the device. $\mathbf{M}$ is the proper mass matrix of the device. This matrix contains coupling terms between the pendulum and the floating body, given by

$$
\mathbf{M}=\left(\begin{array}{cc}
m_{\mathrm{b}}+m_{\mathrm{p}} & 0 \\
0 & m_{\mathrm{b}}+m_{\mathrm{p}} \\
m_{\mathrm{p}}[d \cos \theta-l \cos (\theta+\alpha)] & -m_{\mathrm{p}}[d \sin \theta-l \sin (\theta+\alpha)] \\
-m_{\mathrm{p}} l \cos (\theta+\alpha) & m_{\mathrm{p}} l \sin (\theta+\alpha)
\end{array}\right.
$$

$$
\left.\begin{array}{rl}
S(t) & =\left(\begin{array}{c}
\sum_{j=1}^{3} \sum_{r=1}^{N_{1 j}} S_{1 j r}(t) \\
\sum_{j=1}^{3} \sum_{r=1}^{N_{2 j}} S_{2 j r}(t) \\
\sum_{j=1}^{3} \sum_{r=1}^{N_{3 j}} S_{3 j r}(t) \\
0
\end{array}\right) \\
m_{\mathrm{p}}[d \cos \theta-l \cos (\theta+\alpha)] & \\
-m_{\mathrm{p}}[d \sin -l \sin (\theta+\alpha)] & m_{\mathrm{p}} l \cos (\theta+\alpha) \\
I_{\mathrm{b}}+I_{y}+m_{\mathrm{p}}\left(d^{2}+l^{2}\right)-2 m_{\mathrm{p}} d l \cos \alpha & I_{\mathrm{p}}+m_{\mathrm{p}} l^{2}-m_{\mathrm{p}} d l \sin (\theta+\alpha) \\
I_{y}+m_{\mathrm{p}} l^{2}-m_{\mathrm{p}} d l \cos \alpha & I_{y}+m_{\mathrm{b}} l^{2}
\end{array}\right)
$$

$\boldsymbol{F}_{\text {РTO }}$ represents the action of the PTO.

Computation of the hydrodynamic vector $\boldsymbol{F}_{\mathrm{ex}}$ is done using the classical potential approach with the numerical code AQUAPLUS [9]. Computation of the added mass matrix $\boldsymbol{\mu}_{\infty}$ and the memory function $\mathbf{H}(t)$ is performed using the time-domain seakeeping code ACHIL3D [10]. In the time domain, direct integration of the equation of motion (1) can be done by using fourth-order Runge-Kutta algorithm or it can first transformed in order to remove the convolution

$$
\boldsymbol{S}(t)=\int_{0}^{t} \mathbf{H}(t-\tau) \dot{\boldsymbol{X}}(\tau) \mathrm{d} \tau
$$

Using the Prony method [11], some complex coefficients $(\gamma, \beta)$ can be computed, such as

$$
\mathbf{H}_{i j}(t) \simeq \sum_{r=1}^{N_{i j}} \gamma_{i j r} \mathrm{e}^{i \beta_{i j r} t}
$$

Let

$$
S_{i j r}(t)=\int_{0}^{t} \gamma_{i j r} \mathrm{e}_{j}^{i \beta_{i j r}(t-\tau)} \dot{\boldsymbol{X}}(\tau) \mathrm{d} \tau
$$

The vector $\boldsymbol{S}$ can be rewritten in the form 
By differentiating equation (7), it can be shown [12] that the coefficients $S_{i j r}$ are the solution of a firstorder ordinary differential equation

$$
\dot{S}_{i j r}=\beta_{i j r} S_{i j r}=\gamma_{i j r} \dot{X}_{j}
$$

with the initial conditions $S_{i j r}(0)=0$. Finally, the equation of motion can be written as a simple differential equation

$$
\begin{aligned}
& \left(\mathbf{M}+\boldsymbol{\mu}_{\infty}\right) \ddot{\boldsymbol{X}}=\boldsymbol{F}_{\mathrm{ex}}-\boldsymbol{S}-\mathbf{K}_{\mathrm{H}} \mathbf{Z}-\boldsymbol{F}_{\mathrm{g}}-\boldsymbol{F}_{\mathrm{c}}-\boldsymbol{F}_{\mathrm{PTO}} \\
& \dot{S}_{i j r}=\beta_{i j r} S_{i j r}+\gamma_{i j r} \dot{\boldsymbol{X}}_{j}
\end{aligned}
$$

This last equation can easily be solved numerically, provided the term $\boldsymbol{F}_{\text {Рто }}$ associated with the PTO is defined. If the PTO is a damper, $\boldsymbol{F}_{\text {Рто }}$ is given by

$$
\boldsymbol{F}_{\mathrm{PTO}}=\left(\begin{array}{c}
0 \\
0 \\
0 \\
-B_{\mathrm{PTO}} \dot{\alpha}
\end{array}\right)
$$

where $B_{\text {Рто }}$ is the damping coefficient.

A damper is the classical approach for modelling the PTO in wave energy, but in reality the hydraulic PTO system contains other components apart from pure damping. In the next section, the equation $\boldsymbol{F}_{\text {Рто }}$ is considered and derived for such a hydraulic PTO.

\section{THE HYDRAULIC POWER TAKE-OFF}

\subsection{Introduction}

The main objective of the PTO is to convert the mechanical energy (torque) induced on the pendulum cylinder by the waves into a more useful form. This is generally electricity, but other alternative storing systems could be considered (hydrogen for example). One can transform this mechanical energy into electricity in many ways. For example, the electric generator can be direct drive, as in the Archimedes Wave Swing (AWS) [3], or a gearbox can be used, in order to increase the motion. In the specific case of wave energy converters, hydraulic conversion systems are often used because they are suited to wave energy applications having the following properties.

1. Low speeds and high forces are induced by the waves. In industry, hydraulic systems are commonly used when high forces and small motions are required.

2. Incident power fluctuates in time and amplitude. Coupled with a pneumatic storage device, the PTO can smooth incident power fluctuations.
3. The location is offshore. Hydraulic devices are well known to be robust and require little maintenance, which is an advantage if the WEC is far from the coast.

The SEAREV PTO is composed of five main elements (Fig. 2). First there is a reducing gear used to increase the rotational speed while decreasing the input torque. A double-effect hydraulic linear ram connecting the gear to the floating hull transforms the rotation into a high-pressure form. It pumps fluid from the low-pressure tank to the high-pressure accumulator. The energy is stored in this accumulator by compression of a gas. When there is enough stored energy, the accumulator supplies pressurized fluid at nominal flow to a hydraulic motor coupled to an electric generator. It was assumed that the hydraulic motor is not efficient at part load. Electricity is then generated and the fluid is driven back to the tank at low pressure.

\subsection{Equations of the power take-off}

With the present PTO configuration, the action of the PTO can be reduced to a torque $C_{\text {РTO }}$ applied on the pendulum

$$
\boldsymbol{F}_{\mathrm{PTO}}\left(\begin{array}{c}
0 \\
0 \\
0 \\
C_{\mathrm{PTO}}
\end{array}\right)
$$

The expression for $C_{\text {PTO }}$ is found by considering the state equations for the reducing gear, the accumulator, and the generator.

\subsubsection{The reducing wheel}

As mentioned above, the purpose of the gear is to increase the rotational speed available for the hydraulic cylinder. Indeed, the mean power $W_{\text {ram }}$ recovered by the ram can be approximated as follows

$$
W_{\text {ram }} \simeq Q v\left(P_{\text {accu }}-P_{\text {tank }}\right) \approx 2 V_{\text {ram }} \Omega_{\text {ram }} \Delta P
$$

where $Q v$ denotes the flow of fluid and $\Delta P$ the difference of pressure between the tank and the accumulatoir. Obviously, the instantaneous power varies in time, but the mean flow $Q v$ is directly proportional to the rotational speed $\Omega_{\text {ram }}$ and two times the swept volume $V_{\text {ram }}$ of the double-effect ram. If this hydraulic cylinder is fixed directly on to 


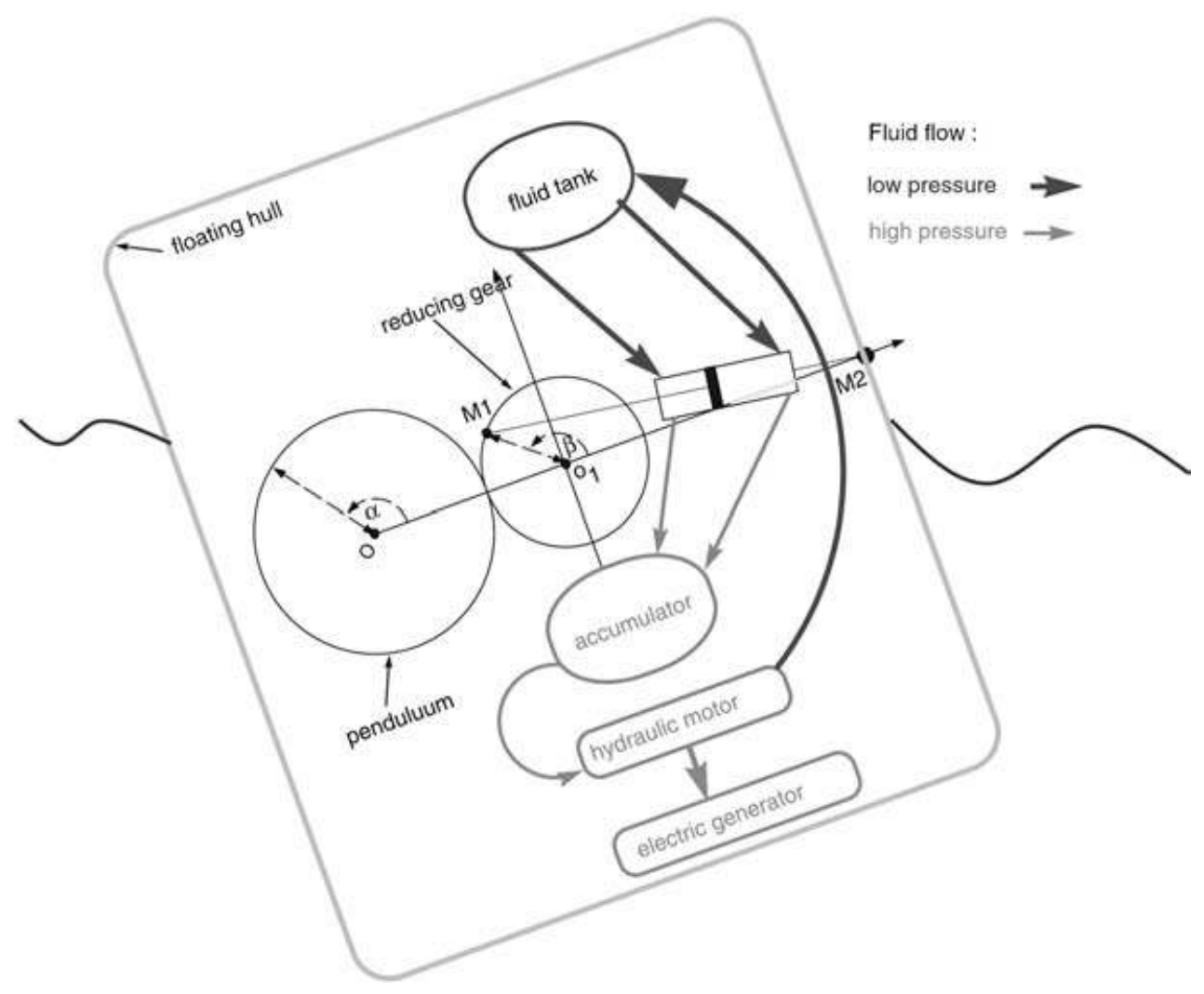

Fig. 2 SEAREV: floating hull and hydraulic PTO

the pendulum (i.e. $\Omega_{\mathrm{ram}}=\dot{\alpha}$ ), a bigger ram is required to recover the same energy. This gear enables the use of a standard hydraulic ram. The kinematical analysis of this gear leads to the following relationships

$$
\begin{aligned}
& \alpha R_{\mathrm{p}}=-\beta R_{\mathrm{rw}} \\
& \dot{\alpha} R_{\mathrm{p}}=-\dot{\beta} R_{\mathrm{rw}} \\
& \ddot{\alpha} R_{\mathrm{p}}=-\ddot{\beta} R_{\mathrm{rw}} \\
& \bar{C}_{\mathrm{hc} / \mathrm{rw}} R_{\mathrm{p}}=-\bar{C}_{\mathrm{PTO}} R_{\mathrm{rw}}
\end{aligned}
$$

where $R_{\mathrm{p} \text { and }} R_{\mathrm{rw}}$ denote the pendulum and reducing wheel radii, $\beta, \dot{\beta}, \ddot{\beta}$ its angular position, speed, and acceleration, $C_{\text {Рто }}$ the torque applied on the pendulum, and $C_{\mathrm{hc} / \mathrm{rw}}$ the torque applied by the hydraulic ram on the reducing gear.

\subsubsection{The hydraulic ram}

Applying the momentum equation gives the torque $C_{\mathrm{hc} / \mathrm{rw}}$

$$
\boldsymbol{C}_{\mathrm{hc} / \mathrm{rw}}=O_{1} \boldsymbol{M}_{1} \wedge \boldsymbol{F}_{\mathrm{hc} / \mathrm{rw}}
$$

with

$$
\boldsymbol{F}_{\mathrm{hc} / \mathrm{rw}}=\boldsymbol{F}_{\mathrm{pr}}+\boldsymbol{F}_{\mathrm{in}}+\boldsymbol{F}_{\mathrm{vc}}
$$

where

$\boldsymbol{F}_{\mathrm{pr}}=\left(P_{1} S_{1}-P_{2} S_{2}\right) \boldsymbol{x}$ is the pressure force;

$\boldsymbol{F}_{\text {in }}=m_{\text {piston }} f(\beta, \dot{\beta}, \ddot{\beta})$ is the inertia force;

$\boldsymbol{F}_{\mathrm{vc}}$ is the viscous and coulomb friction.

$\boldsymbol{F}_{\mathrm{in}}$ and $\boldsymbol{F}_{\mathrm{vc}}$ are given by the motion (i.e. depend on $\beta, \dot{\beta}, \ddot{\beta}$, the piston mass $m_{\text {piston }}$, the viscosity, etc.) of the hydraulic cylinder (revolution and translation). Then the details need to be added to the model of the most important force: $\boldsymbol{F}_{\mathrm{pr}}$.

Let $S_{i}, P_{i}, v_{c_{i}}, q_{t_{i}}$, and $q_{a_{i}}$ be respectively the cross-section, pressure, volume, flow from the tank, and flow to the accumulator of the ram chamber $i$ $(i=1,2)$ (Fig. 3). The main problem in calculating the pressure effort is to take account of the compressibility of the fluid. Usually, the fluid is assumed to be incompressible, but it is useful to use the bulk modulus $\varepsilon$ of the fluid (i.e. an apparent compressibility) to avoid numerical instability due to the stiffness of the resulting numerical model. Doing this, it is possible to find a relationship between the pressure evolution in each chamber $\dot{P}_{i}$ of the cylinder 


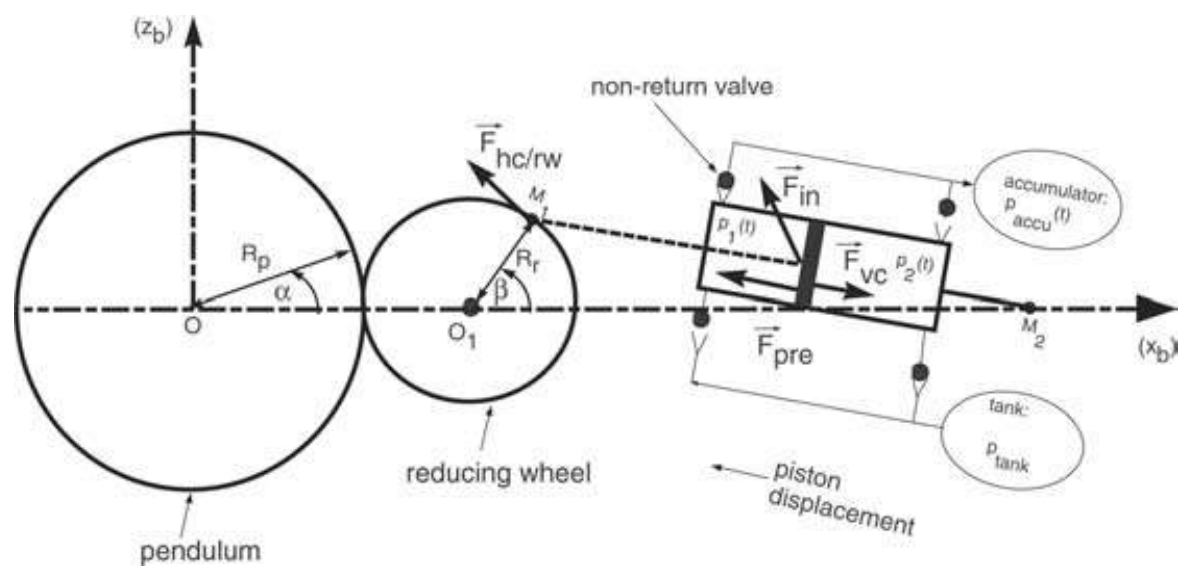

Fig. 3 Scheme of the hydraulic PTO

and the displacement of the piston $\dot{x}$

$$
\dot{P}_{1}=\frac{\varepsilon\left(q_{t_{1}}+q_{a_{1}}-S_{1} \dot{x}\right)}{v_{c_{1}}}
$$

where

$$
\begin{array}{ll}
q_{t_{1}}=S_{1} \dot{x} & \text { if } \dot{x}>0 \text { and } P_{1}<P_{\text {tank }}, \text { else } q_{t_{1}}=0 \\
q_{a_{1}}=S_{1} \dot{x} & \text { if } \dot{x}<0 \text { and } P_{1}>P_{\text {accu }}, \text { else } q_{a_{1}}=0 \\
\dot{v}_{c_{1}}=\dot{x} &
\end{array}
$$

and

$$
\dot{P}_{2}=\frac{\varepsilon\left(q_{t_{2}}+q_{a_{2}}+S_{2} \dot{x}\right)}{v_{c_{2}}}
$$

with

$$
\begin{array}{ll}
q_{t_{2}}=-S_{2} \dot{x} & \text { if } \dot{x}<0 \text { and } P_{2}<P_{\text {tank }}, \text { else } q_{t_{2}}=0 \\
q_{a_{2}}=-S_{2} \dot{x} & \text { if } \dot{x}>0 \text { and } P_{2}>P_{\text {accu }}, \text { else } q_{a_{2}}=0 \\
\dot{v}_{c_{2}}=-\dot{x} &
\end{array}
$$

\subsubsection{The high-pressure accumulator}

This high-pressure tank is characterized by three parameters:

(a) the initial inflated pressure $P$;

(b) the initial inner fluid volume $V_{0}$;

(c) the volume $V_{\mathrm{m}}$ of the accumulator.

Under the assumption of isentropic compression, the evolution of the pressure $P_{\text {accu }}$, volume $V_{\text {accu }}$, and energy stored $E_{\text {accu }}$ can be linked to the flow from the hydraulic cylinder using the following relations

$$
\begin{aligned}
\frac{\dot{P}_{\mathrm{accu}}}{P_{\mathrm{accu}}} & =-\gamma \frac{\dot{V}_{\mathrm{accu}}}{V_{\mathrm{accu}}} \\
\dot{V}_{\mathrm{accu}} & =q_{a_{1}}+q_{a_{2}}+q_{\mathrm{motor}} \\
E_{\mathrm{accu}} & =-\int_{V_{\mathrm{m}}-V_{0}}^{V_{\mathrm{accu}}} P_{\mathrm{accu}}(\tau) \dot{V}_{\mathrm{accu}}(\tau) \\
& =\frac{P_{0}\left(V_{\mathrm{m}}-V_{0}\right)}{\gamma-1}\left[\left(\frac{P_{0}}{P_{\mathrm{accu}}}\right)^{(1-\gamma) / \gamma}-1\right]
\end{aligned}
$$

\subsubsection{The hydraulic motor and electric generator}

The hydraulic motor and electric generator form a unit that converts the energy stored in the accumulator into electricity. It is described by its nominal power $W_{\text {nominal }}$, its supply pressure $P_{\text {nominal }}$, the initial inflated pressure of the accumulator $P_{0}$ (with $P_{0}=P_{\text {nominal }}$ ), and the transformation efficiency $\eta_{\text {motor }}$, which includes mechanical and electrical losses. Electricity production starts when the stored energy in the accumulator $E_{\text {accu }}$ exceeds a given level $E_{\text {start }}$ and stops when the energy drops below a given level $\left(E_{\text {accu }}<E_{\text {stop }}\right)$

$$
q_{\text {motor }}= \begin{cases}\frac{W_{\text {nominal }}}{\eta_{\text {motor }}\left(P_{\text {nominal }}-P_{\text {tank }}\right)} & \text { if } E_{\text {accu }}>E_{\text {start }} \\ 0 & \text { if } E_{\text {accu }} \leqslant E_{\text {stop }}\end{cases}
$$

Equations (13) to (22) define the behaviour of the PTO. Solving them numerically together with the governing equations of the pendulum and floating hull gives the position vector of the system $\boldsymbol{X}$ and all the inner PTO data (pressure, produced power, 
stored energy, etc.) that are useful for monitoring the wave energy converter.

\section{THE SIMULINK MODEL}

All the governing equations were implemented using the MATLAB/Simulink tool. This method of simulation enables an intuitive 'block' approach: each component (floating hull, hydraulic cylinder, etc.) is defined by its own model. Figure 4 represents the model of the accumulator. The input of this block is the total flow $\left(\dot{V}_{\text {accu }}\right.$ in equations (21)). The output is the pressure in the accumulator $P_{\text {accu }}$ and two command signals. The first one controls the relief valve that limits the pressure inside the accumulator and the second one switches on the motor if $E_{\text {accu }}>E_{\text {start }}$ and switches off the motor if $E_{\text {accu }}<E_{\text {stop }}$. All the blocks are linked together like the real physical components, thus bringing together the full set of governing equations from the simplest element (the pressurized fluid accumulator in Fig. 4) to the whole SEAREV double pendulum model (Fig. 5).
This provides a versatile toolbox of components for testing different configurations.

The ODE solver used is a third-order BogackiSharpine scheme, provided by MATLAB, with a time-step $\mathrm{d} t=0.1 \mathrm{~s}$.

\section{TIME-DOMAIN SIMULATIONS}

\subsection{The PTO configuration}

Dimensions of the floating hull and the pendulum are given in Table 1 and some characteristics of the PTO in Table 2. A new parameter $P_{\max }$ that defines the maximum pressure acceptable in the accumulator is included in order to ensure the safety of the highpressure system. When the pressure reaches this value, there is a relief valve that limits the pressure inside.

In order to assess the influence of this highly realistic PTO system, it was compared with the performance of a simple PTO model, defined only by its damping coefficient $B_{\mathrm{PTO}}$. The optimal value of

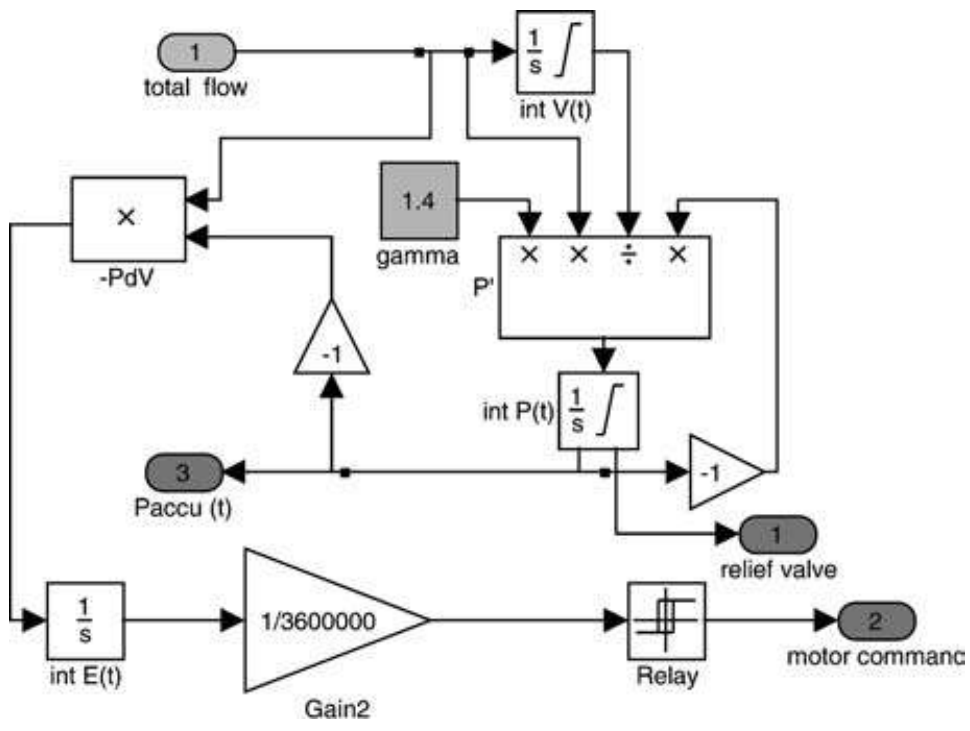

Fig. 4 Global view of the SEAREV MATLAB/Simulink model

Table 1 SEAREV parameters

\begin{tabular}{lllllll}
\hline$m_{\mathrm{b}}(\mathrm{t})$ & $I_{\mathrm{b}}\left(\mathrm{t} \mathrm{m}^{2}\right)$ & $m_{\mathrm{p}}(\mathrm{t})$ & $I_{y}\left(\mathrm{t} \mathrm{m}^{2}\right)$ & $l(\mathrm{~m})$ & $d(\mathrm{~m})$ & $R_{\mathrm{p}}(\mathrm{m})$ \\
\hline 551 & $4.31 \times 10^{7}$ & 393 & $4.62 \times 10^{6}$ & 0.9213 & -9.213 & 4.85 \\
\hline
\end{tabular}

Table 2 PTO parameters

\begin{tabular}{|c|c|c|c|c|c|c|c|c|c|c|c|c|c|}
\hline $\begin{array}{l}R_{\mathrm{rw}} \\
(\mathrm{m})\end{array}$ & $\begin{array}{l}x_{m 2} \\
(\mathrm{~m})\end{array}$ & $\begin{array}{l}x_{m 1} \\
(\mathrm{~m})\end{array}$ & $\begin{array}{l}S_{1}=S_{2} \\
\left(\mathrm{~cm}^{2}\right)\end{array}$ & $\begin{array}{l}\varepsilon \\
(\mathrm{Pa})\end{array}$ & $\phi$ & $\begin{array}{l}V_{m} \\
\left(\mathrm{~m}^{3}\right)\end{array}$ & $\begin{array}{l}V_{0} \\
\left(\mathrm{~m}^{3}\right)\end{array}$ & $\begin{array}{l}P_{\text {tank }} \\
\text { (bar) }\end{array}$ & $\begin{array}{l}P_{\max } \\
\text { (bar) }\end{array}$ & $\eta_{\text {motor }}$ & $\begin{array}{l}E_{\text {start }} \\
(\mathrm{kW} \mathrm{h})\end{array}$ & $\begin{array}{l}E_{\text {stop }} \\
(\mathrm{kW} \mathrm{h})\end{array}$ & $\begin{array}{l}B_{\text {PTO }} \\
(\mathrm{kN} \mathrm{m} / \mathrm{rad} \mathrm{s})\end{array}$ \\
\hline 1.225 & 3 & 0 & 100 & $10^{9}$ & 0.99 & 10 & 0.01 & 1 & 250 & 1 & 4 & 0.1 & 504 \\
\hline
\end{tabular}




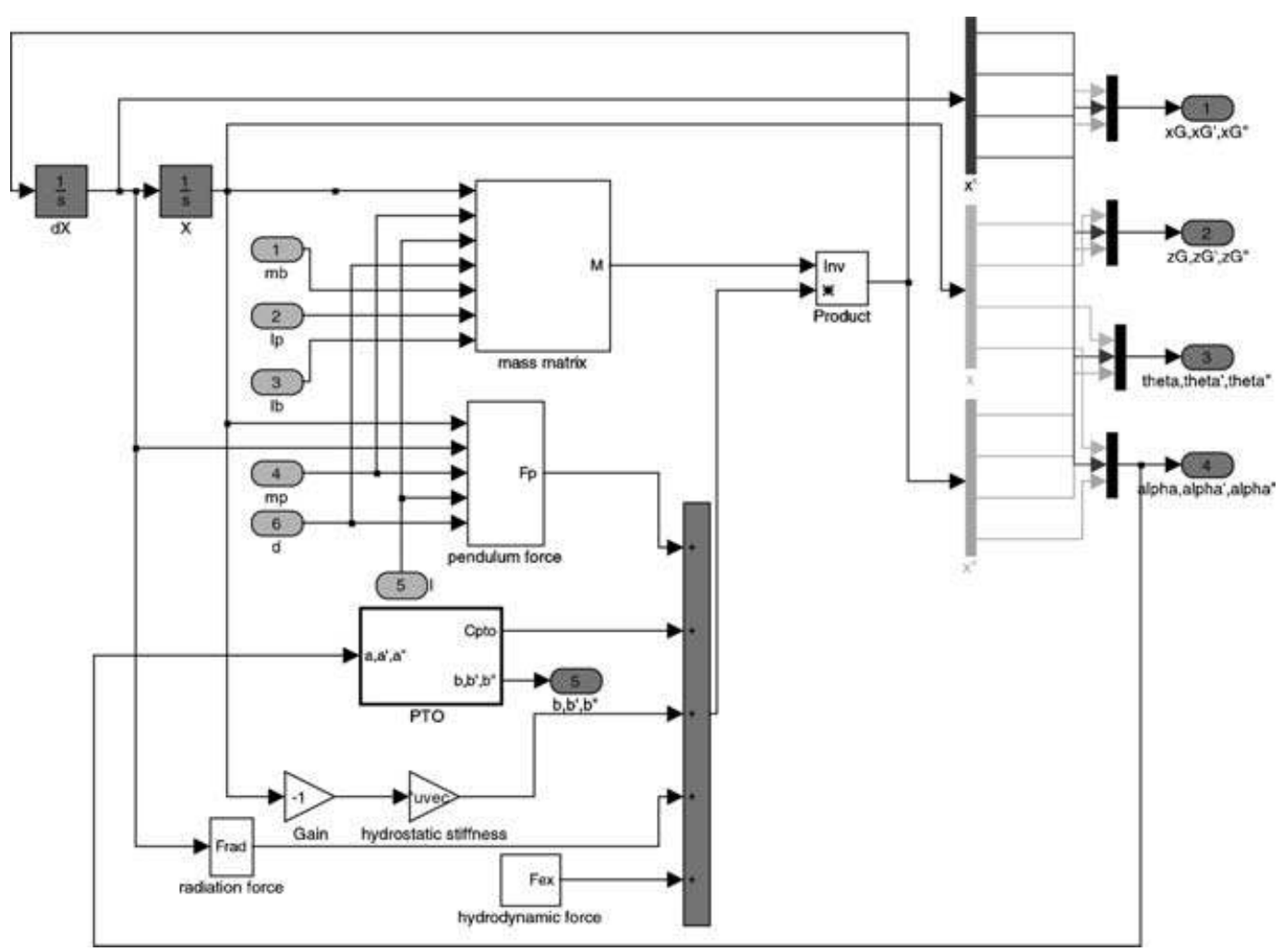

Fig. 5 The accumulator model

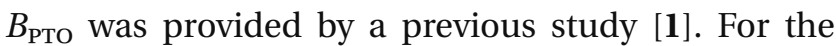
hydraulic cylinder, the effect of the friction and inertia forcs were assumed to be negligible. The ratio of maximum swept volume to maximum chamber volume is defined by the coefficient $\phi$. This coefficient avoids numerical instability in the pressure equations (18) and (20) by limiting the minimum value of the chamber volume $\left(v_{c_{1}}\right.$ and $v_{c_{2}}>0$ if $\phi<1$, whereas $v_{c_{1}} \geqslant 0$ and $v_{c_{2}} \geqslant 0$ if $\left.\phi=1\right)$. Pressure drops (drains, valves, etc.) into the fluid circuit are also neglected.

All component values are realistic, so the results presented hereafter represent a SEAREV equipped with existing components. The final purpose of these tests is to assess the influence of two parameters on the SEAREV performances:

(a) the supply pressure of the hydraulic motor ( 20 bar $\leqslant P_{\text {nominal }}=P_{0} \leqslant 200$ bar);

(b) the power of the coupled electric generator $\left(20 \mathrm{~kW} \leqslant W_{\text {nominal }} \leqslant 400 \mathrm{~kW}\right)$.

The same time domain wave, computed using the energy spectrum, is considered for each simulation, but different specific heights from 1 to $5 \mathrm{~m}$ are used. The behaviour of the components of the PTO are more precisely detailed for different tests cases (Table 3) in order to point out the inner parameters acting on the energy production.

Table 3 Test parameters

\begin{tabular}{|c|c|c|c|c|c|c|c|c|c|}
\hline$H_{\mathrm{s}}(\mathrm{m})$ & \multicolumn{9}{|c|}{1} \\
\hline$W(\mathrm{~kW})$ & \multicolumn{3}{|c|}{50} & \multicolumn{3}{|c|}{100} & \multicolumn{3}{|c|}{200} \\
\hline $\begin{array}{l}P_{0} \text { (bar) } \\
\text { Test number }\end{array}$ & $\begin{array}{l}50 \\
\text { al }\end{array}$ & $\begin{array}{l}100 \\
\mathrm{a} 2\end{array}$ & $\begin{array}{l}150 \\
\mathrm{a} 3\end{array}$ & $\begin{array}{l}50 \\
\mathrm{a} 4\end{array}$ & $\begin{array}{l}100 \\
\text { a5 }\end{array}$ & $\begin{array}{l}150 \\
\mathrm{a} 6\end{array}$ & $\begin{array}{l}50 \\
\text { a7 }\end{array}$ & $\begin{array}{l}100 \\
\mathrm{a} 8\end{array}$ & $\begin{array}{l}150 \\
\text { a9 }\end{array}$ \\
\hline$H_{\mathrm{s}}(\mathrm{m})$ & \multicolumn{9}{|c|}{3} \\
\hline$W(\mathrm{~kW})$ & \multicolumn{3}{|c|}{50} & \multicolumn{3}{|c|}{100} & \multicolumn{3}{|c|}{200} \\
\hline$P_{0}$ (bar) & 50 & 100 & 150 & 50 & 100 & 150 & 50 & 100 & 150 \\
\hline Test number & b1 & b2 & b3 & b4 & b5 & b6 & b7 & b8 & b9 \\
\hline
\end{tabular}




\section{RESULTS AND DISCUSSION}

\subsection{The threshold torque $C_{\text {limit }}$}

The first test deals with a low energetic sea state. Figure 6 represents the energy recovered by the SEAREV during half an hour, that is to say, the sum of the energy stored in the accumulator plus the energy generated by the electric generator during this period. The best performances $\left(E_{\text {extracted }}>7 \mathrm{~kW} / \mathrm{h}\right)$ are achieved with the lowest pressure $\left(P_{0} \leqslant 50\right.$ bar). Looking closer at tests al and a3, it appears that the greater the pressure $P_{0}$, the smaller the motion of the ram (regarding $L_{\mathrm{a} 1}$ and $L_{\mathrm{a} 3}$ in Fig 7). Consequently, the ram pumps less fluid into the accumulator and less energy is generated [see $q_{a}(\mathrm{a} 1)$ and $q_{a}(\mathrm{a} 3)$ in Fig. 8]. However, the flow ratio $f r_{\mathrm{a} / \mathrm{a} 3}$ is bigger than the pressure ratio $p r_{\mathrm{a} 1 / \mathrm{a} 3}$. Recalling the estimation of the power recovered by the ram [equation (13)] a better energy recovery with a low pressure is expected

$$
\begin{aligned}
f r_{\mathrm{a} 1 / \mathrm{a} 3} & =\frac{q_{a}(\mathrm{a} 1)}{q_{a}(\mathrm{a} 3)} \\
p r_{\mathrm{a} 1 / \mathrm{a} 3} & =\frac{P_{0}(\mathrm{a} 3)}{P_{0}(\mathrm{a} 1)}
\end{aligned}
$$

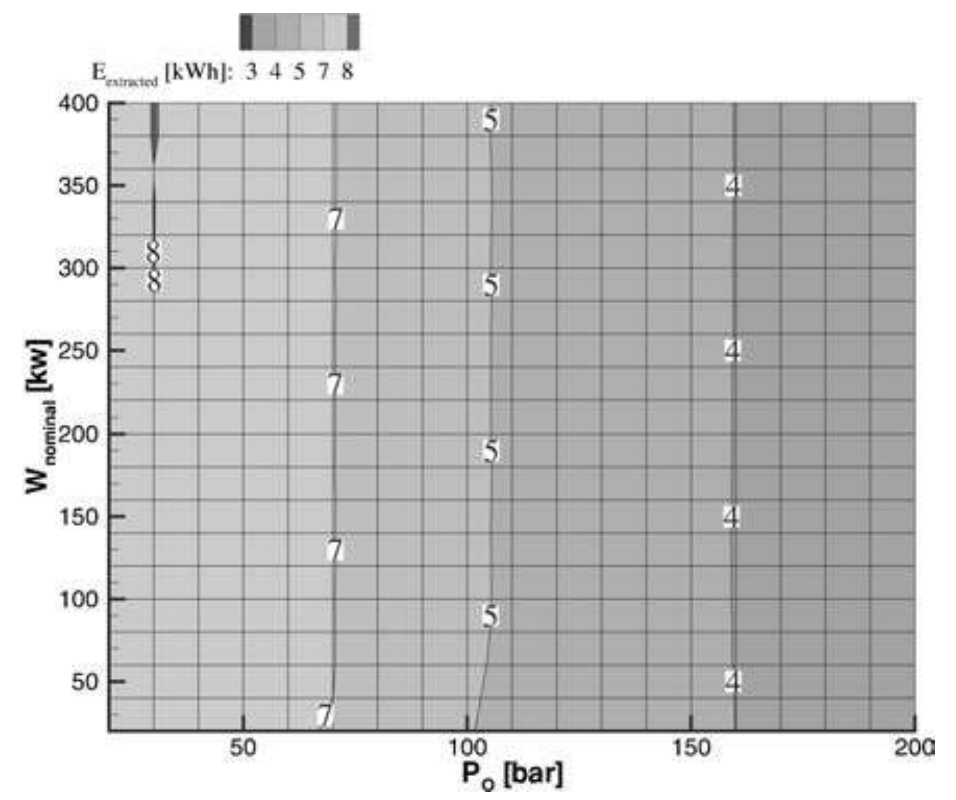

Fig. 6 Recovered energy for the sea state: $\left(H_{\mathrm{s}}, T_{\mathrm{p}}\right)=(1 \mathrm{~m}, 8 \mathrm{~s})$

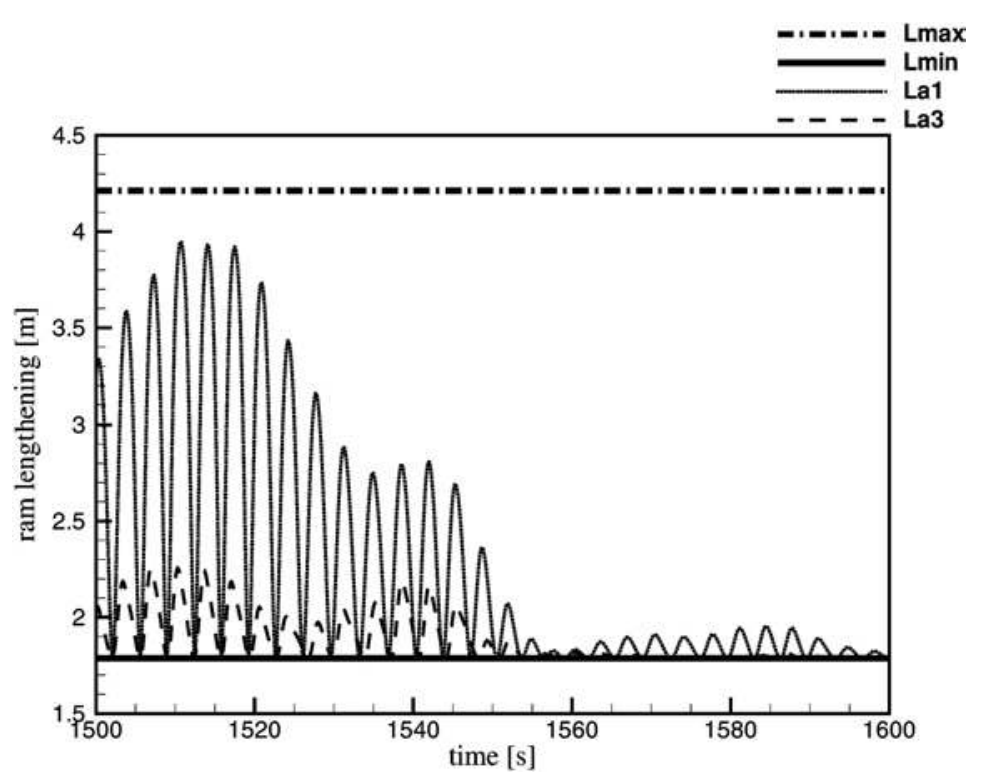

Fig. 7 Hydraulic cylinder lengthening for tests al and a3 


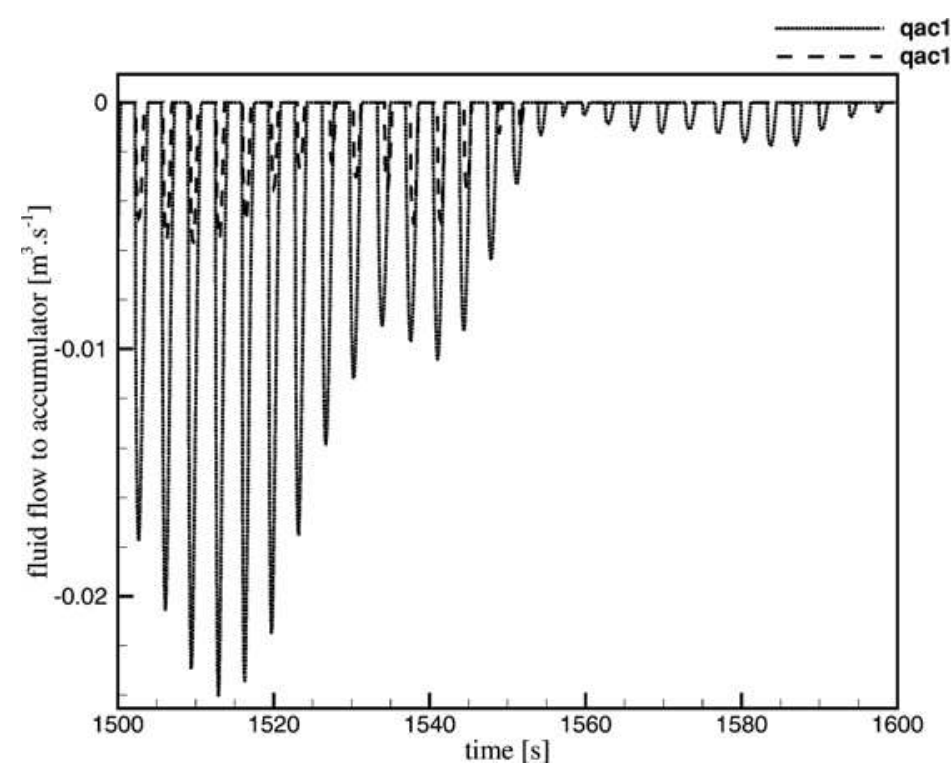

Fig. 8 Fluid flow from chamber 1 into the accumulator for tests al and a3

It can be seen that sometimes (see, for example, $L_{\mathrm{a} 3}$ for $1550 \mathrm{~s}<t<1600 \mathrm{~s}$ in Fig. 7) the hydraulic cylinder does not move. To pump fluid from the tank to the accumulator, the pendulum has to generate a torque $C_{\text {pendulum }}$ greater than the threshold torque $C_{\text {limit }}$. This threshold torque is proportional to the pressure $P_{\text {accu }}$, the sections $S_{1}$ and $S_{2}$, and the radius $R_{\mathrm{rw}}$. If the torque applied by the pendulum to the ram is lower than the threshold torque, then the hydraulic will not begin moving and there will be no energy absorption. As increasing the pressure $P_{0}$ leads to an increase in the threshold torque $C_{\text {limit }}$ of the PTO, this leads to a decrease in the performance of the SEAREV for low energetic sea states.

In this case, the power of the electric generator does not influence the behaviour of the WEC.

\subsection{The underpowered/overpowered configurations}

The next test configuration deals with a medium energy sea state (Fig. 9). In order to maximize the energy production, it can be seen that parameters such as 70 bar $<P_{0}<170$ bar and $80 \mathrm{~kW}<W_{\text {nominal }}$

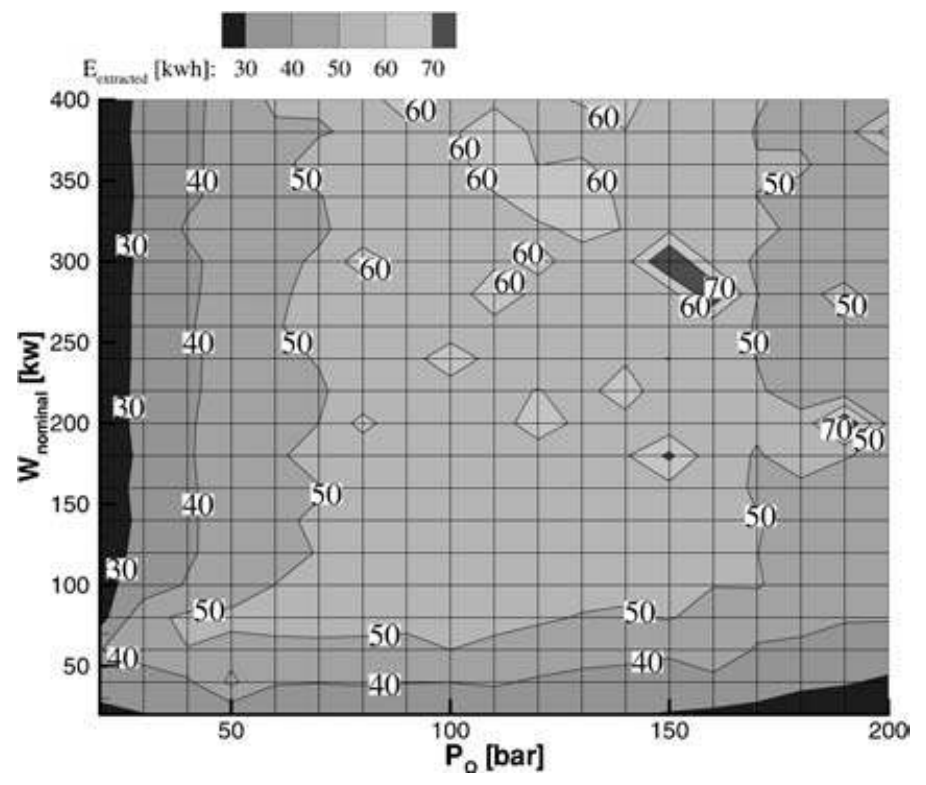

Fig. 9 Recovered energy for the sea state: $\left(H_{\mathrm{s}}, T_{\mathrm{p}}\right)=(3 \mathrm{~m}, 8 \mathrm{~s})$ 
should be chosen. Indeed, for higher pressure configurations (170 bar $\left.<P_{0}\right)$, performances are still limited by the high level of the threshold torque. For lower pressures $\left(P_{0}<70\right.$ bar $)$, performances are limited by the motion of the pendulum: the rotational speed of the pendulum cannot increase sufficiently to compensate for the low-pressure level with a high fluid flow. Therefore, the absorbed power is lower.

The influence of the generator's power rate is much more important for medium energy sea conditions and above. If an underpowered electric generator is installed ( $W_{\text {nominal }}<80 \mathrm{~kW}$ in this case), this cannot convert all the incident energy into electricity: the pressurized fluid accumulator inflates until the limit pressure is reached, after which the relief valve limits the pressure (see cases b1, b2, b3 in Fig. 10).

Looking at Fig. 11, it can be seen that there are three behaviours affecting electricity production.

1. The first one (b3) is the result of underpowered PTO: the production of electricity is continuous (after the first stage of accumulator inflation). This is an advantage for the connection to the grid, but the PTO cannot transform all the mechanical power into electricity. The result is a loss in performance.

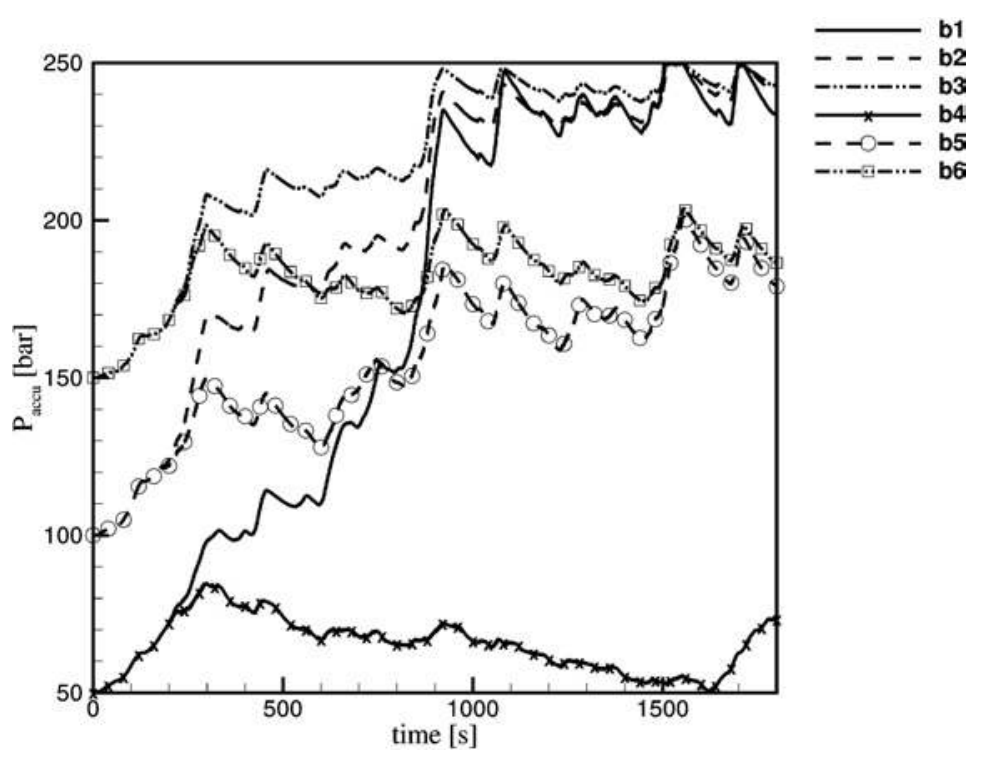

Fig. 10 Accumulator pressure evolution

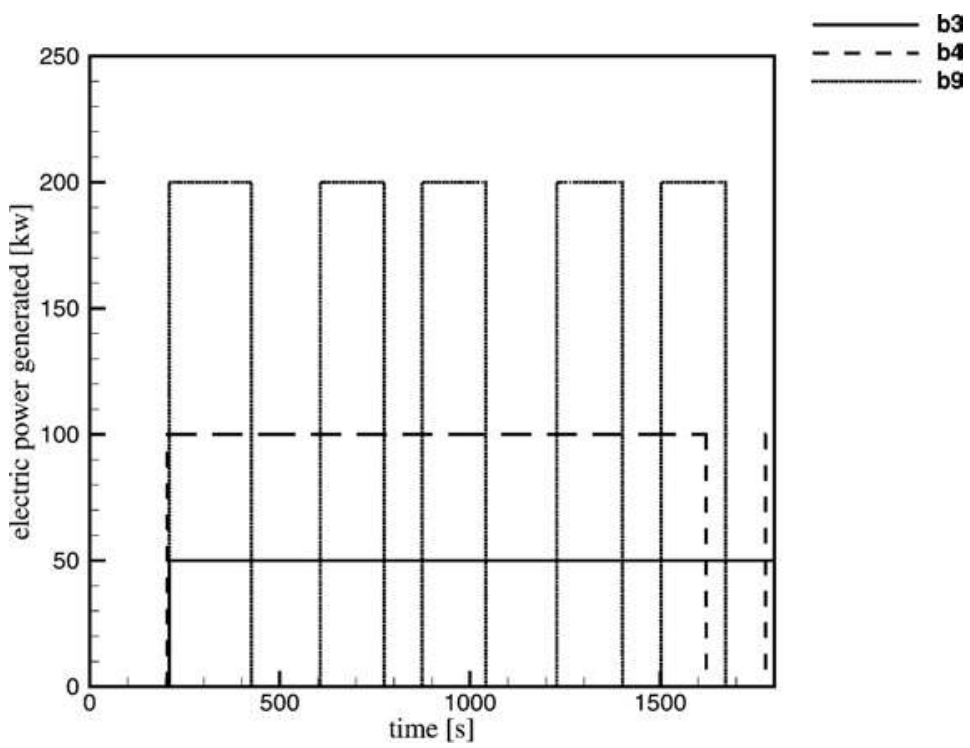

Fig. 11 Evolution of the generated electric power 
2. The second one (b9) is the result of an overpowered PTO: when the electricity generator is switched on, the accumulator is emptied quicker than it is filled, the energy stored reaches the minimum level $E_{\text {stop }}$, and the generator is switched off. The resulting electricity generation is then discontinuous.

3. The last one (b5) represents a good compromise: the well-sized PTO allows continuous electricity production without the efficiency leakage due to accumulator saturation (see case b5 in Fig. 10).

The last set of tests were conducted on a highenergy sea state (Fig. 12). The high incident power moved the parameters to higher values $180 \mathrm{bar}<P_{0}$ and $300 \mathrm{~kW}<W_{\text {nominal }}$. All the other configurations are inadequate: in some cases $\left(120 \mathrm{bar}<P_{0}\right)$ the underpowered generator leads to accumulator saturation and in others cases the underpowered hydraulic components (ram and accumulator) limit the capacity of the SEAREV to transform mechanical energy into hydraulic energy.

\subsection{Hydraulic PTO versus damper}

As mentioned above, the value of the damping coefficient $B_{\text {Рто }}$ is the result of an optimization study [1]. It is of great interest to compare the performances of this simplified PTO model to a more realistic one. The results (Table 4) show that the realistic model can achieve, and sometimes exceed, the performance of the linear damper for all the sea states with a hydraulic PTO. However, it is necessary to adapt the configuration $\left(P_{0}, W_{\text {nominal }}\right)$ to each sea state, whereas with the damper, the damping coefficient was modelled as constant.

\section{CONCLUSION}

In this paper the main governing equations of the new WEC SEAREV were presented and the resulting numerical simulator detailed with its first results. This allowed the behaviour of not only the floating hull but also each component of the PTO system to be studied.

Simulations showed that with a hydraulic PTO, there is a threshold torque that prevents the cylinder from moving in small seas. This threshold torque depends on the pressure level and geometric parameters such as the ram section and the reducing wheel radius. At the other extreme, when the sea state grows, electricity production is limited by the capacity

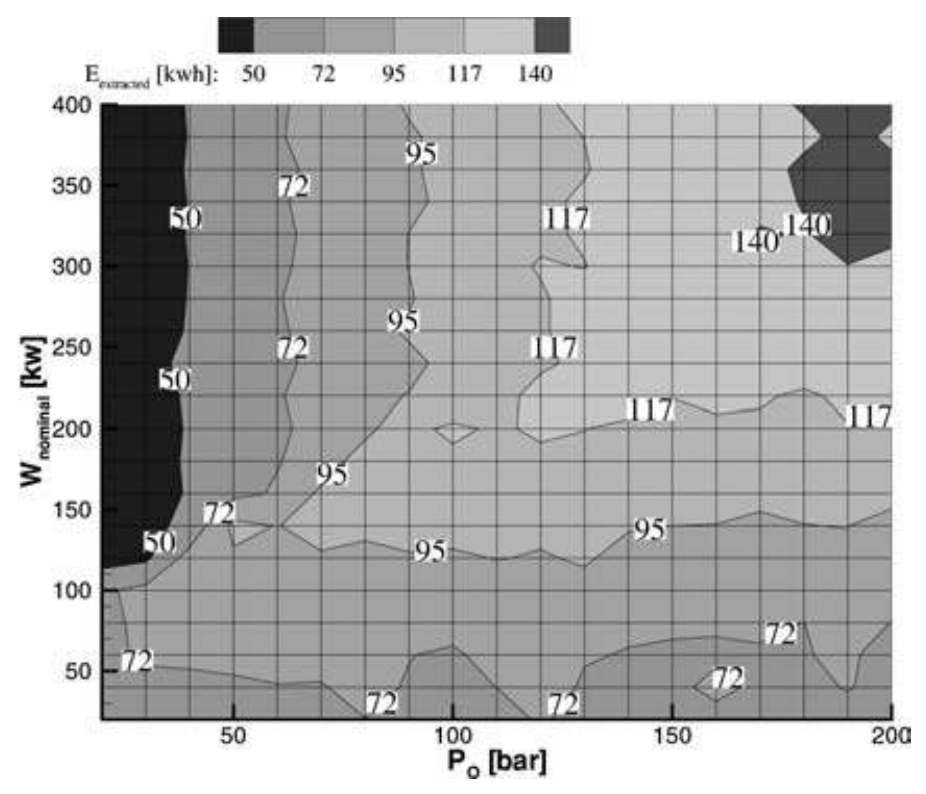

Fig. 12 Recovered energy for the sea state: $\left(H_{\mathrm{s}}, T_{\mathrm{p}}\right)=(5 \mathrm{~m}, 8 \mathrm{~s})$

Table 4 Best hydraulic PTO versus damping viscous PTO

\begin{tabular}{lccc}
\hline & & \multicolumn{2}{c}{ Hydraulic PTO } \\
\cline { 3 - 4 }$H_{\mathrm{s}}(\mathrm{m})$ & $\begin{array}{l}\text { Viscous damper } \\
E_{\text {extracted }}(\mathrm{kW} \mathrm{h})\end{array}$ & $E_{\text {extracted }}(\mathrm{kW} \mathrm{h})$ & $P_{\mathbf{0}}(\mathrm{bar}), W_{\text {nominal }}(\mathrm{kW})$ \\
\hline 1 & 8 & 8 & $(30,300)$ \\
3 & 61.9 & 82 & $(150,300)$ \\
5 & 132.2 & 154.9 & $(190,340)$ \\
\hline
\end{tabular}


of the PTO to transform all the incident power to electricity without leakage. In order to enlarge the bandwidth of the SEAREV and to optimize its efficiency, the next step of development will deal with the control of the PTO and the way needed to adapt it to different sea conditions.

\section{REFERENCES}

1 Babarit, A. and Clément, A. H. Shape optimisation of the SEAREV wave energy converter. In Proceedings of the World Renewable Energy Congress IX, Florence, August 2006.

2 Hals, J., Bjarte-Larsson, T., and Falnes, J. Optimum reactive control and control by latching of a wave-absorbing semisubmerged heaving sphere. In Proceedings of the OMAE'02, 21st International Conference on Offshore mechanics and arctic engineering, Oslo, June 2002, pp. 1-9.

3 Sà da Costa, J., Sarmento, A. J. N. A., Gardner, F., Beirão, P., and Brito Melo, A. Time domain model of the AWS wave energy device. In Proceedings of the 6th European Wave and Tidal Energy Conference, Glasgow, UK, September 2005.

4 de O. Falcao, A. F. Modelling and control of oscillating-body wave energy converters with hydraulic power take-off and gas accumulator. In Proceedings of the 6th European Wave and Tidal Energy Conference, Glasgow, UK, September 2005.

5 Bracewell, R. H. Frog and PS frog: a study of two reactionless ocean wave energy converters. $\mathrm{PhD}$ Thesis, Lancaster University, 1990.

6 Rawson, K. J. and Tupper, F. C. Basic ship theory, vol. 1, 3rd edition, 1983 (Longman, London).

7 Clément, A. H., Babarit, A., Gilloteaux, J. C., Josset, C. and Duclos, G. The SEAREV wave energy converter. In Proceedings of the 6th European Wave and Tidal Energy Conference, Glasgow, UK, September 2005.

8 Cummins, W. E. The impulse response function and ship motions. Schiffstechnik, 1962, 491-502.

9 Delhommeau, G., Ferrant, P., and Guilbaud, M. Calculation and measurement of forces on a high speed vehicle in forced pitch and heave. Appl. Ocean Res., 1992, 14(2), 119-126.

10 Clément, A. H. Using differential properties of the green function in seakeeping computational codes. In Proceedings of the 7th International Conference on Numerical Ship Hydrodynamics, 1999, 6(5), 1-15.

11 Baron Riche de Prony. Essai expérimental et analytique sur les lois de la dilatabilité des fluides élastiques et sur celles de la force expansive de la vapeur de l'eau et de la vapeur de l'alcool à différentes températures. Ecole Polytechnique 1, 1795, Cahier 2, pp. 24-76.

12 Babarit, A. and Clément, A. H. Optimal latching control of a wave energy converter. In Proceedings of the 6th European Wave and Tidal Energy Conference, Glasgow, UK, September 2005. 